\title{
DOES THE FAULT SYSTEM OPTIMALLY CONTROL PRIMARY ACCIDENT COSTS?
}

\author{
Guido Calabresi*
}

I

For the purposes of this article, I shall assume that the sole aim of any system of accident law is the minimization of the sum of $(a)$ accident costs and (b) the cost of avoiding accident costs. I include in the latter the "cost" in pleasure forgone of undertaking a relatively less desirable but less accident-prone activity, or-what is really the same thing-the cost of engaging in an activity in a safer but more expensive or less pleasurable way. ${ }^{1}$

I make this assumption for analytical purposes only. I do not for a moment believe this to be the only aim of accident law. The aim that a system of accident law be "just" or "fair" could only through a rather unhappy twisting of words-and valuation of things which cannot be valued-be made to come within my "cost" formulation. Yet fairness is ultimately a goal which any system of accident law must meet. Everything cannot be discussed at once, however, and, although I believe that the fault system can be shown to be quite "unfair" both relatively and absolutely, I will leave that demonstration to another piece.

I shall also leave out of this discussion certain categories of accident costs even though their control fits within the aim I have hypothesized for the system. Specifically, I shall exclude what I have elsewhere called secondary accident costs, the costs of social and economic dislocations which all too often follow the immediate accident, especially if the initial cost burden is left unspread. ${ }^{2}$ A full discussion of fault as a minimizer of accident costs would, of course, take these costs into account. I do not do so here because the ways of minimizing these costs are so different from the ways of minimizing other accident costs that dealing with both together leads only to confusion. It can be demonstrated, however, that the fault system is both absolutely and in comparison with other possible systems a very poor "spreader" or "minimizer" of secondary costs.

- Professor of Law, Yale University.

1 This statement takes no position on the crucial question of who should decide the relative costs of accidents and their avoidance. Thus, this decision may be made collectively, by individuals in the market, or through a mixture of collective and individual decisions. The statement also allows for the inclusion of moral values in the sum of accident costs and accident avoidance costs where that is desired. See pp. 453-58 infra.

${ }^{2}$ See, e.g., Calabresi, Changes for Automobile Claims, Views and Overviews, 1967 U. ILI. L.F. 600, 602-603 (1967) [hereinafter cited as Views and Overviews]; Calabresi, Fault, Accidents and the Wonderful World of Blum and Kalven, 75 YALE L.J. 216, 2x8-219 (I965) [hereinafter cited as The Wonderful World]; Calabresi, Some Thoughts On Risk Distribution and the Law of Torts, 70 YaLE L.J. 499, 5I7527 (I96I) [hereinafter cited as Thoughts on Risk Distribution]. 
Finally, I shall deal only tangentially with administrative costs of accident systems (which can be termed tertiary accident costs). These can only be dealt with in relation to other aims. The question as to such costs is always whether they are worthwhile in terms of the fairness or the cost savings they accomplish. ${ }^{3}$ Since I have excluded "fairness" and "secondary costs" from this article, I shall not discuss administrative costs in relation to them. I shall, however, consider the administrative costs of the fault system in relation to the aim which I have elsewhere called the minimization of the primary costs of accidents. ${ }^{4}$ That is what is left when fairness and secondary costs are excluded.

The question that my hypothesized aim of the system requires us to ask is this: What system of accident law yields the optimal combination of accident-causing activities, direct accident costs, and costs of reducing accident costs? I have described this "decision for accidents" in detail elsewhere." What is important for us here is to realize that the choice for some accident costs is inevitable. The issue, thereforc, becomes not whether we have some accident costs and some desirable though accident-prone activities, but what level we want of each and, more significantly, what system we wish to use to determine the level of each. The fault system is only one of several possible systems for making this determination.

It may be well to begin by defining what I mean by the fault system. In general terms, I mean the fault system as it is usually described today-not some other system which would involve liability in almost every instance but which nonetheless continued to use the term fault. Specifically, I mean a system (a) which determines the existence of liability on a case-by-case basis, (b) usually with a jury, $(c)$ on the basis of certain general indicia of behavior more or less subsumed under a standard defined in terms of what a reasonable man is presumed to be able to foresee and do, (d) under which liability can be insured against, and $(e)$ under which assessment of the extent of liability depends primarily on the extent of damages caused rather than on the degree of wrongdoing by the party held liable. The fault system I have in mind may be either a comparative or a contributory negligence system. There are, of course, many other systems which give a role to fault but which differ greatly from the current fault system. (An example would be any of various nonfault compensation systems which contemplate a supplementary array of noninsurable tort fines based on degree of wrongdoing rather than damages caused.)

I must now return to the basic question: what system do we wish to have for determining the level of accident costs in relation to accident-prone activities? There are two ways which could in theory be used to decide the question: the collective way

\footnotetext{
${ }^{3}$ See, e.g., Calabresi, The Decision for Accidents: An Approach to Nonfault Allocation of Costs, 78 HaRv. L. REv. 713, 714 n.3 (1965) [hereinafter cited as The Decision for Accidents]; Views and Overviews, supra note 2 , at 605 .

${ }^{4}$ See, e.g., The Decision for Accidents, supra note 3 , at 7 r5.

Id. at $7 \mathrm{I}_{4}-2 \mathrm{I}$.
} 
(which I call specific deterrence) and the market way (which I call general deterrence). Neither is feasible alone, but they serve to define the limits within which possible systems of primary accident cost avoidance-systems for answering the question I have just asked-must operate. All such systems are mixed in the sense that they involve some collective and some market action. The fault system itself is a prime example of a mixed system. In order to see what the mixture is, the pure systems must be described. ${ }^{6}$

The collective system would decide each possible issue involving a choice between accident-prone behavior and fewer accidents by a collectively determined rule. To the extent such rules are meant to be roo per cent effective, ${ }^{7}$ they represent clear societal choices that, whatever pleasure or profit an individual would derive from an activity, society's view of the activity and its accident potential demand its prohibition. We have, in our society, many such rules. For example, people below a certain age are not allowed to drive automobiles, regardless of the pleasure a twelveyear-old or his parents would derive from the boy's driving. In theory, similar collective judgments could be made as to every possible activity, and as to every possible manner of performing each activity. We would each be told when we could drive, what kind of car to drive, whether to drive at night, and so forth. Wherever there exists the possibility of accidents, activities would be regulated by collective decisions weighing the danger of accidents against the worthiness of the acts or activities which could cause the accidents.

Such a system would, of course, be not only impossible but intolerable. Collective decisions are hard to make intelligently. It may be possible to decide collectively that seat belts are worthwhile and hence mandatory. But it is harder to determine precisely what kind of seat belts are best for everyone. And it is harder still to decide whether, given seat belts, it is best for society to let any given individual drive at any given time on any given street. In general, collective decisions proscribing an act or activity as too dangerous in relation to the pleasure it gives are likely in three circumstances: (a) where the act or activity is so clearly dangerous that it seems worthwhile to undertake the substantial expense of examining and deciding collectively what we give up by barring it (driving by minors might be an example), (b) where an act or activity has, through a particularly clamorous accident or series of accidents, become politically very visible so that once again the fact finding needed

\footnotetext{
'A total description of either system, but especially of the market system, is a complicated undertaking requiring a work of book length. Accordingly, I am only sketching out the systems here.

T Such rules may not be meant to be totally effective. They may, for instance, be enforced by taxes or fines which are designed to put pressure on most people to abstain from the undesirable activity and still allow those who really wish to engage in it to do so at the cost of paying the collectively determined penalty. This has the effect of limiting the activity rather than abolishing it. Such limitations are, in fact, mixtures of market and collective control systems. See pp. 453-54 infra. There is a significant difference between the way we control those activities which we wish to stamp out and the way we control those which we collectively decide to discourage. The use of stigma and other nonmonetary penalties is perhaps the major difference. Even where we want to stamp out an activity we may not be $100 \%$ successful, but that is another matter.
} 
for intelligent collective regulation of the activity becomes feasible (regulation of firecrackers and many types of work safety laws might fit this category), and (c) where the act or activity is of dubious desirability or morality apart from the accidents it may cause (here, almost any accident costs attributable to the activity seem to justify prohibition, because there is nothing on the other side of the balance or, better, because we have decided collectively to give no weight to the pleasure individuals may get from this activity).

Most accident-causing activities fall outside these categories, however. There are few activities which we would wish to proscribe without a good deal of information as to their accident-causing potential. And we are not willing to undertake the expense involved in deciding whether to proscribe most other activities in whole or even in part. Yet we feel uncomfortable if failure to proscribe an activity implies a collective decision that any number of accidents caused by that activity are worth their costs. We would, in short, be very uncomfortable if the collective decision between accident costs and accident-prone activities were the only control over accident costs available to us.

Fortunately, the collective method is not the only control available. There is also the market method. In its pure form the market method would let the level of activities and accidents be determined entirely by individual market decisions. To the extent driving caused accident costs, these would be assessed to driving, and anyone who cared to pay these costs would be entitled to drive. The higher the costs for any particular type of driving, the fewer the people who would wish to undertake the activity. To the extent the cost of driving by twelve-year-olds became prohibitive, this would simply indicate that in the market the activity had been shown not to be worth its costs. To the extent engagement in the activity was reduced or the activity modified as a result of bearing accident costs, this would represent a societal choice derived through the market that the activity was worthwhile only to a certain extent, or only if modified. The more accident costs are attributable to an activity or to a way of doing it, the greater would be the pressure on it to change or to diminish. But in all events, the degree to which this occurred would be the result of individual market decisions made in the light of the costs, including accident costs, involved.

There are at least as many problems with the market approach as there are with the collective approach. This is not the place to go into all of them. Some of the problems are simply applications of more general difficulties with the resource allocation theory of welfare economics on which the market approach is based. I have discussed these elsewhere and will not do so here. ${ }^{8}$ Other problems arise from difficulties which become especially significant when welfare economics theory is applied to the accident field. These are worth specific discussion.

\footnotetext{
${ }^{8}$ See, Thoughts On Risk Distribution, supra note 2, at nn.I7-22 and accompanying text; The Wonderful World, supra note 2, at n.5.
} 
We often do not wish people to choose for themselves among ordinary goods and services, and we are much less likely to let people choose for themselves when the choice involves the taking of lives and limbs. The point is obvious; we do not let a murderer murder simply because he can find and fully compensate a willing victim. We attempt to make a collective prohibition of certain types of killing regardless of the pleasure of which this deprives the would-be murderer and regardless of his ability to pay his would-be victim. We call such behavior immoral and make a collective judgment against it. Short of the extreme of murder there are, as I have already noted, many other acts and activities-be they drunken driving or running a red light-which we do not believe are best controlled by letting each individual weigh his desire to engage in the activity against the cost of the activity to society. This would suffice to explain why every society uses some collective controls as well as some market controls.

A more general problem with market control of accidents exists, however: we have no adequate supply curve of willing victims. In the typical case of market determination of how many goods or services are to be produced, there is both a demand for and a supply of the particular good or service, and the price can be set by the market. In accident costs, the situation is considerably more complex. There is a demand for victims. There are plenty of people who wish to engage in activities, like driving, which are accident-prone. They are willing to pay for the accident costs of automobiles just as they are willing to pay for the steel costs of automobiles. As costs rise, they may buy fewer cars, but that is precisely how the demand side of a market normally operates. A supply side of willing accident victims is not so easily described. Yet without a supply side it is impossible to derive a market value for arms, legs, and lives.

The question of how one ought to go about determining the cost of an arm or leg is immensely complex. For the moment it is enough to say that we cannot count on the market to make this determination for us in the way we rely on it to determine the cost of steel. This means that even if we opt for substantial market control of accident-causing activities, we must still decide collectively what the cost of an accident is. And this in turn means that we must decide how we are going to make that cost determination.

The difficulties of making an intelligent cost decision, however, are every bit as great if we opt for a collective control system as if we opt for a market control system. In fact, they are much the same. So this difficulty is no reason to prefer collective to market controls. The point is that even if we wanted to have a pure market control system, we could not have it, for we would inevitably have to make some collective decisions as to the cost of arms and lives. The market could in complicated ways help us in making these decisions, but it could not do it alone. ${ }^{8}$

${ }^{D}$ To the extent accident costs involve property damages or lost earnings, a market system would use open market values for equivalent property. To the extent the accident costs involve lives and limbs, a 
Finally, a market control system necessitates making a decision as to who ought to bear the cost of an accident when more than one act or activity is involved. Here again collective determination is often needed. Is a pedestrian-auto accident a cost of driving or of walking? Is an accident resulting from a defective steering wheel a cost of auto making, of auto selling, or of driving? These questions must be answered if we are to use a market system of controls. They must also be answered if we are using a collective control system. (Do we regulate driving or walking? Do we regulate auto making, auto selling, or driving?) As with costing of accidents, the point is not whether it is easier to do in a collective control system or in a market system. It is hard in both. The point is that we cannot have a pure market system since in many instances a collective decision must be made as to whom the cost belongs.

It may come as a surprise but all that has gone before is really by way of introduction. My object in this paper is not to examine the advantages and disadvantages of collective and market systems in detail. It is rather to examine the fault system as a mixed system and see if it does well either what a collective system or what a market system would seek to accomplish. Does the fault system represent an effective system of collective control of accident costs? Or does it represent an optimal system of market control? Or does it perhaps represent an intelligent mixture of the two? To answer these questions, one must consider how the fault system attempts to answer the questions which any system of primary accident cost avoidance must face. These, as should have been apparent from my discussion of market control, are (a) what is the cost of an accident? and $(b)$ to what degree should each of several parties involved in an accident be held responsible for it (whose cost is it)?

The characteristics of the fault system as a decider of what the costs of an accident are can be easily spelled out. The decision is made on a case-by-case basis rather than according to a schedule of damages. And the decision is normally made by a jury. These two characteristics entail several consequences. The first and most obvious is that they involve substantial administrative expense. Whatever the merits of assessing each case as a separate instance and having a jury determine the damages, there can be no doubt that the procedure is a costly one. Whether the result is worth the expense depends in part on whether such individualized jury cost determinations are more accurate than other, less expensive devices. But it also depends on whether individualized decisions by a jury are needed anyway to decide who should be deemed responsible for the accident. If an adequate determination of whose cost it is requires a case-by-case decision and a jury, then having a case-by-

market system could try to extrapolate from the amount of payment people demand in exchange for bearing a known risk of such an injury. For rather complicated reasons, this latter method is far from a satisfactory way of valuing most personal injury costs. A market control systcm of accident costs would make the best use it could of whatever such indications of market valuations are available. A collective control system would in all probability attach less weight to them. 
case jury determination of damages adds little, if any, expense. If, instead, case-bycase determinations of to whom the cost belongs are undesirable, then jury case-bycase assessment of damages is almost certain to cost more than it is worth. This suggests that evaluation of how the fault system determines what the costs of an accident are will largely depend on an evaluation of how it determines whose costs they are.

The second consequence of jury case-by-case determination is that the assessment of damages inevitably entails some moral judgment on the activity held liable. The theory of the fault system would separate liability from damage assessment. But in practice the jury is inevitably influenced in assessing damages by how worthy it deems the activity held liable to be. The effects of this must be carefully noted.

First, this manner of assessing damages substantially diminishes the role of market control in the fault system. Market control assumes individual decisions as to the desirability of different activities in the light of what the activity costs society. This in turn means that if costs are to be assessed collectively (because no other way is available), that assessment must be independent of the desirability of the activities which cause the cost. For the desirability of activities is precisely what the market would let individuals decide for themselves once the cost determination is made. The fault system, instead, makes the cost determination depend, in part at least, on a jury's judgment of the desirability of the activities involved. This does not mean the fault system is undesirable; it only means that it is not the market system.

Second, to the extent damages are based in part on a judgment of worthiness of cost-causing acts and activities, this collective judgment is made on a case-by-case basis, by a jury, after the accident has occurred. The question must be asked: is this the way we wish to have collective moral judgments introduced into the system? Is this, in other words, the best way to decide collectively the relative worth of accident-prone activities, assuming we want a collective decision at all?

In fact, both whether we want some collective assessment of the worthiness of activities, and how we want that collective judgment to be made, depend in large part on how we wish to decide what activity is responsible for accident costs. This again suggests that evaluation of the fault system as a decider of what the costs of an accident are depends largely on an evaluation of the fault system as a decider of whose costs they are. ${ }^{10}$ And to this difficult question-the core of this articlewe must now turn.

\footnotetext{
${ }^{10} \mathrm{~A}$ complete cvaluation of the fault system as a decider of what the costs of an accident are is more complex than the text may suggest. A conclusion that the fault system's jury, case-by-case method of deciding who should bear accident costs is indefensible suggests that the same method is probably undesirable for determining what the costs are. It cannot conclude the issue, however. In order to do that, I would need to examine in detail (a) how a market system would optimally value costs, (b) how a collective system mould optimally value costs and $(c)$ what is likely to be the best compromise between the two. In doing this, practical difficulties with other possible methods would have to be considered (e.g., the likelihood that schedules of damages would be allowed to get out of date). Limitation's of
} 
I propose to consider the question in three parts: First, would the fault system be used to decide who should bear the cost of an accident if we sought to get as close to a pure market system as is possible? ${ }^{11}$ Second, would the fault system be used if we sought to achieve close to a fully collective system of accident cost control? And third, if neither of these is true, does the fault system represent an intelligent mixture of the two systems?

A pure market system would allocate accident costs to the acts or activities (or combinations of them) which could avoid the accident costs most cheaply. This is the same as saying the system would allocate the costs to those acts or activities which an arbitrary initial bearer of accident costs would find it most worthwhile to subsidize in order to obtain that modification of behavior which would lessen accident costs most. This formulation implies several things. If there were no transaction costs and no information costs associated with paying people to alter their behavior, it would not matter (in terms of market control of accidents) who bore the accident costs initially. Regardless of who was initially liable, transactions would occur to change the behavior of every person so long as each change caused a greater reduction in accident costs than in pleasure. ${ }^{12}$ Since in reality transactions are often terribly expensive, it is often not worthwhile spending both the cost of the transaction and the amount needed to induce someone else to diminish his accident-causing behavior. As a result the accident cost is not avoided by society, while another allocation which eliminated or lessened the transaction cost would have been possible and would have resulted in the accident cost's being avoided. The aim of the pure market determination of what activity should be held liable is to find this other allocation.

An overly simple example may be in order. Suppose car-pedestrian accidents currently cost \$100. Suppose also that if cars had spongy bumpers the total accident costs would only be \$ro. Suppose finally that spongy bumpers cost $\$ 50$ more than current bumpers. Assuming no transaction costs, spongy bumpers would become

length require that all these issues, though relevant and perhaps important, be kept outside the scope of the current article. I should make clear, however, that, on the basis of my consideration of the problem, I am convinced that the statement in the text is a valid one.

11 The notion that the fault system could conceivably be an optimal system of market control-an optimal system of resource allocation-generally strikes lawyers as absurd on its face, and not worth examining. Unfortunately, many economists with whom I have discussed the matter take, at first glance, exactly the opposite position. In addition, Blum and Kalven at times seem to defend the faule system on precisely these grounds, see, e.g., Blum \& Kalven, The Empty Cabinet of Dr. CalabresiAuto Accidents and General Deterrence, 34 U. CHI. L. REv. 239, 244, 257 (1967) [hereinafter cited as The Empty Cabinet]; W. Blum \& H. Kalven, Public Law Perspectives on a Private Law prodlem-Auto Compensation Plans 63, 69 (1965) [hereinafter cited as Public Law Penspectives]. In view of these differences of opinion, the question demands detailed attention.

${ }^{12}$ See generally Coase, The Problem of Social Cost, 3 J. LAw \& Econ. I (Ig60). On these assumptions no misallocations of costs would ever be possible. See Calabresi, Transaction Costs, Resource Allo. cation and Liability Rules, Ir J. LAW \& EcoN. 67 (I968) [hereinafter cited as Transaction Costs]. 
established regardless of who was held responsible for car-pedestrian accidents. If car makers were liable they would prefer to spend $\$ 50$ for the new bumpers plus \$ro in accident damages, instead of \$roo for accident damages. If pedestrians were held responsible (and could foresee the costs) they would prefer paying car makers $\$ 50$ to put in spongy bumpers to bearing \$roo in damages. The total cost to pedestrians if they subsidized the car makers would be $\$ 50$ (subsidy) plus \$Io (damages borne), and this would be cheaper than incurring $\$ 100$ in damages. Exactly the same result would occur if an arbitrary third party, say television makers, were held liable initially. They, too, could lessen costs to themelves by paying car makers to put in rubber bumpers. And this is simply because the cost of avoiding the accident is in all instances less than the cost of compensating for it. Wherever this is so, and wherever it costs nothing to negotiate and pay a subsidy (and people have adequate knowledge), the market will seek the cheapest way and avoid the accident.

Now let us alter the example to add transaction costs. Assume that any allocation other than leaving the cost where it falls (on the pedestrian) costs $\$ 5$. Assume also that for pedestrians to subsidize anyone involves very high transaction costs, say $\$ 65$. (This is because it is expensive to gather pedestrians together for bargaining purposes and to handle the problem of would-be free loaders-people who say, "I won't pay, because if you do I'll get the benefit of spongy bumpers anyway.") ${ }^{13}$ Assume finally that it costs $\$ 30$ for television makers to subsidize. What would happen in our example? If car makers were held liable they would bear $\$$ roo plus perhaps $\$ 5$ (the cost of allocating the loss); they could avoid this in the future by putting in spongy bumpers at $\$ 50$, paying the $\$ 10$ in damages which would still remain, plus perhaps the same $\$ 5$ in administrative costs (assuming the unlikely event that these remained constant). Since $\$ 65$ is less than $\$ 105$, they would clearly put in spongy bumpers. If pedestrians were held liable they would bear only $\$$ roo in accident costs. But to get spongy bumpers put in would cost them $\$ 50$ (subsidy) plus $\$ 65$ (transaction costs), and they would still bear \$ro in accident costs; \$r25 is more than \$roo and a change to spongy bumpers would not seem worth its costs. But the absence of spongy bumpers would in fact entail an unnecessary cost to society of the difference between \$roo (accidents costs when borne by pedestrians) and $\$ 6_{5}$ (the cost to society when car makers are held liable). If television makers were held liable,

\footnotetext{
${ }^{13}$ The freeloader is the person who refuses to be innoculated against smallpox because the risks of smallpox to him, given the fact that almost everyone else is innoculated, is less than the risk of harm from the innoculation; if enough people are freeloaders it becomes necessary to compel innoculation to avoid smallpox epidemics. He is also the person who refuses to join a union; because the fact that most other workers are union members assures him of the benefits of unionization without the cost. The use of compulsion in these areas suggests that the problem of freeloaders is crucial whenever many people must agree to bear a cost in order to bring about a change favorable to all of them. The problem would not be crucial if nonpayers could be excluded from the benefits of the change, but such cxclusion is often extremely expensive. It is precisely that expense which justifies compulsion. Cf., Transaction Costs, supra note 12 .
} 
the figures would be $\$ 100$ plus $\$ 5$ with no spongy bumpers, as against $\$ 5^{\circ}$ (subsidy) plus $\$ 30$ (transaction costs) plus \$1o (remaining accident costs) plus perhaps $\$ 5$ (administrative costs). $\$ 95$ is less than $\$ 105$, and spongy bumpers would probably be established. But this result would have been accomplished in a more expensive (less efficient) way than if car makers had been liable, for $\$ 30$ in unnecessary transaction costs would have been imposed on society. Clearly in my example it would be best to make auto makers liable. ${ }^{14}$

One may well ask, but if this is the case why not require spongy bumpers in the first place (why not make a collective decision rather than a market one)? If things were as simple as my example, and if making a collective decision and enforcing it were cheaper than the market way, the question would be well put. The answer is, of course, that there will be cases where a collective rule is best. But, first, it is not always cheaper to do things collectively. And second, as things get more complicated than my example, often the only way we can know whether it is best to put in spongy bumpers or not, and how many to put in, is to pick the party who can make that decision best, allocate the costs to him, and let him (hopefully spurred by competition) decide.

The question for the pure market system is, then, how should we in practice

\footnotetext{
14 Throughout these examples I have ignored the question of long-run changes in the level of the activities discussed. I have acted as if the only effect of the different liability rules proposed is to affect the decision to install spongy bumpers. Cf. Coase, stupra note 12. In fact, liability rules can have a broader, long-run effect. They can change the relative profits of the activities involved and so affect the relative number of car makers and cars, pedestrians, and television makers in my examples. See, Transaction Costs, supra note 12 , at 67 .

This long-run effect presents no particular theoretical problems. If there are no transaction' costs, the same kind of transactions which occurred to cure short-run misallocations will occur to curc long-run ones. Thus whatever reductions in cars, pedestrianism, and televisions cost least in pleasure forgone will become established. See id. at 67-69, correcting The Decision for Accidents, supra note 3, at 730 n.28, $73 \mathrm{I} \mathrm{n.30;} \mathrm{and} \mathrm{The} \mathrm{Wonderful} \mathrm{World,} \mathrm{supra} \mathrm{note} \mathrm{2,} \mathrm{at} \mathrm{231-32} \mathrm{and} \mathrm{accompanying} \mathrm{footnotes.} \mathrm{If} \mathrm{onc}$ assumes transaction costs, as one must, the theoretical problem remains the same as in the short-run case: namely, allocating costs to the (now, long-run) cheapest cost avoider so as to make worthwhile changes likely, and at the same time avoid uninecessary transaction costs.

In practice the problem is more difficult. Long-run transaction costs are almost always prohibitive, and judgments as to who is likely to be the cheapest long-run cost avoider (judgments as to the rclative desirability in the market of a few more cars as against a few more pedestrians) are harder to make than judgments as to short-run cost avoiders (judgments as to who is likely to be in the best position to determine whether spongy bumpers are worth their costs). This means that in many situations we may as well ignore the long-run judgment because one guess is as good as another. If this is so, concentrating on the short-run judgment is the best we can do.

A more complicated situation occurs, however, when we can guess which activity is likely to be the cheapest long-run cost avoider, and that activity is not the cheapest short-run cost avoider. Suppose we believe that diminishing pedestrianism is the cheapest long-run cost avoider, but introducing spongy bumpers in some kinds of cars is the cheapest short-run change. How can we achieve both? Sometimes we may not be able to; then we must choose what cost avoidance seems most important and what cost avoider we are most sure of. At other times we can achieve both by combining market devices (like allocation of liability to car makers) to induce spongy bumpers where they are desirable, with collective inducements or controls (like fixed governmental subsidies to car makers paid out of fixed taxes on pedestrians) to increase the number of cars relative to pedestrians. See, Transaction Costs, supra note 12, at 71-72. The permutations are almost infinite, but the practical decisions are no harder than they would be if we sought to achieve primary cost control mainly through collective decisions.
} 
determine who is the cheapest (i.e., most efficient) cost avoider?-how should we determine who is in the position of the car maker of my example for each category of accidents? In almost every area we can make some rough guesses, based on intuitive notions or on undifferentiated and unanalyzed experiences, as to who clearly is not the cheapest cost avoider and who may be. These can be defined further by controlled experiments; but such experiments are unlikely to be carried out, because they cost too much. Even in this uncertain state, however, there are criteria which can be used for finding who, pending more information, is likely to be the cheapest cost avoider. I must now set these out and compare them with the criteria the fault system uses.

The first criterion for picking the cheapest cost avoider in conditions of uncertainty is this: The optimal relationship between avoidance costs and administrative costs must be sought. This simply means that if finding (or allocating costs to) the cheapest cost avoider is very expensive it may be better to allocate costs to a slightly less cheap cost avoider. For any cost savings achieved by the seemingly better allocation are not worth the costs borne to find it. If placing accident costs on drivers according to miles driven results in nearly as much auto-pedestrian accident cost avoidance as a charge on drivers according to age and accident involvement, and if the latter costs much more to administer, in practice the cheapest cost avoiders may well be drivers categorized by miles driven rather than on the basis of accident involvement by age of driver.

The second criterion is: The maximum degree of internalization of costs consistent with the first criterion should be sought. This is a bit of economic jargon for a concept that is not too difficult. I have said that we often do not know for certain what allocation of costs would in theory accomplish the cheapest cost avoidance, but in most cases we can rule out a great many allocations as almost certainly being no good. We may not know whether pedestrians or drivers are the cheapest cost avoiders of auto-pedestrian accidents, but we may nonetheless be sure that either is better than taxpayers in general or television makers. If this is so, we should rule out any allocation which externalizes costs from pedestrians or drivers to taxpayers in general, unless this allocation of costs is so much cheaper administratively that administrative savings make up for the lack of accident cost savings. Externalization occurs in three ways. The frrst is externalization by insufficient subcategorization. The second is externalization by transfer. The third is externalization as a result of inadequate knowledge.

Allocation of pedestrian-auto accident costs to driving in general (through a fixed tax on all drivers) might be an example of externalization by insufficient subcategorization. If it turned out that teenage drivers were responsible for a disproportionate number of auto-pedestrian accident costs, the allocation described would result in externalizing some of the cost from this subcategory of driving to the broader category of driving in general. Had the accident costs been allocated to 
drivers by accident involvement according to age group, the result would be that all drivers would bear a portion of the cost but teenage driving would bear a greater share. Of course, since subcategorization is expensive it will at some point be cheaper to have some externalization to a broader category than to subcategorize infinitely. That is why I described the criterion as the greatest internalization possible consistent with the optimal level of administrative costs. ${ }^{\mathbf{1 5}}$

Allocation of pedestrian-auto accident costs to pedestrians might be one of many possible examples of externalization by transfer. If the result of this allocation is that society picks up the tab through social insurance paid out of general taxes because most pedestrians are inadequately covered, what looked like a decision to put the costs on pedestrians rather than drivers actually results in neither bearing the costs. Under these circumstances, the proper decision on cost bearers should concentrate on whether drivers or taxpayers are likely to be the cheapest cost avoiders, for the practical effect of allocating costs to pedestrians as the apparent cheapest cost avoiders is to make taxpayers bear the costs.

Externalization by inadequate knowledge would occur if pedestrians to whom auto-pedestrian costs were allocated could not (because of inadequate knowledge or for psychological reasons) foresee the risk of bearing accident costs involved in walking. Pedestrians, we are assuming, would be the cheapest cost avoiders if they could accurately convert into money the risk they take by walking. But if they cannot, because of inadequate knowledge, putting the cost on them would not affect their behavior, and would have as little accident control effect as scattering the cost. ${ }^{16}$

The third criterion for picking the cheapest cost avoider in practice is rather different from the first two. It is: Allocate accident costs in such a way as to maximize chances that errors in allocation are corrected in the market. This criterion assumes that often we will be unsure of the choice of cheapest cost avoider. It further assumes that, despite transaction costs, a tendency exists for the market to find the cheapest cost avoider and to induce him by payments to alter his behavior. It therefore urges selection, to the extent that we are unsure of who the cheapest cost avoider is, of that loss bearer who can enter into transactions most cheaply. This means that if the initial loss bearer chosen is not, in fact, the

\footnotetext{
${ }^{15}$ This degree of internalization may be no internalization at all. If primary accident cost avoidance is quite unimportant with respect to a class of accidents and even the slightest categorization is very expensive, the optimal level of administrative costs may require no categorization. In such instances, generalized social insurance paid out of regular taxes may be the best solution. Cf. A. Conaro et al., Automobile Accident Costs and Payments 52 (1964), and Conard, The Economic Treatment of Automobile Injuries, 63 Mich. L. Rev. 279, 289-9 ( 1964$)$. Such a result merely recognizes that "living" in general is the broadest category of activity of which all other activities are in some sense subeategorics. To conclude that in some situations no categorization is worth its costs does not, of course, suggest that this will be true as to most accident situations. See, The Decision for Accidents, supra note 3, at 733-34.

${ }^{16}$ A slightly different, but equally undesirable, result would occur if pedestrians overestimated the risk involved in walking. In such situations too much pressure to alter or abstain from walking would be exerted.
} 
cheapest cost avoider we have at least minimized the obstacle which transaction costs impose on the market's finding and influencing the behavior of the cheapest cost avoider. Obviously, this criterion does not suggest picking a party who clearly is not the cheapest cost avoider simply because he can pay subsidies easily. It suggests that to the extent we are unsure of our choice among possible cheapest cost avoiders, the best subsidizer in the group is our best bet.

The fault system meets none of these criteria adequately. It ignores altogether most of the considerations relevant to the internalization criterion. In choosing who should be liable, the fault system pays no attention to which of the possible cost bearers is most likely to be aware of the risk involved. As a result, although it may seem to choose a party who can avoid the accident cheaply, it in fact often picks one who will bring about very little cost avoidance. This is best seen by considering why workmen's compensation brought about such a change in industrial accident cost avoidance. In theory, it should have made no difference whether the workers as a group, or the employers as a group, were held liable. As I have explained elsewhere, the same accident cost would have become a part of the employment contract whoever bore the loss. ${ }^{17}$ In fact it made an enormous difference, because employees consistently underestimated the likelihood of injury and therefore did not take or demand safety precautions consonant with the risk. To employers that same risk was a cold cost figure which could easily be compared with the cost of safety devices, and the result was that many safety devices were adopted. The fault system, by concentrating on the theoretical cost avoidance abilities of the individual faulty workers, ignored the far more important fact that accident costs allocated to individual workers tended to exert little economic pressure for safety because workers not yet injured systematically underestimated the risks of injury. As a result, these costs were largely externalized from either of the two possible cheapest cost avoiders-faulty workers and nonfaulty employers. An allocation to nonfaulty employers could and did lead to cheaper cost avoidance, because it resulted in adequate evaluation of the risk of injury and in its full retention as an economic factor internal to the employment contract. Workmen's compensation thus eased the problem in one area. But it made no change in the fault system, which still ignores the question of which possible loss bearer is most likely to be adequately informed of the costs involved.

The fault system ignores altogether the effect of externalization by transfer. In allocating losses between the faulty pedestrian and the nonfaulty driver, it may seem to consider the cost avoidance potential of each. But in doing this it never asks the question of who really pays. If the effect of putting the cost on the pedestrian is that the tab is paid by social insurance raised from general tax revenues, behavior by pedestrians will not be at all affected. It would be far better for cost avoidance to put the cost on the driver, making it a cost of driving, and thus retaining it on

\footnotetext{
${ }^{17}$ See, e.g., The Wonderful World, stura note 2, at 223-24.
} 
the pedestrian-driver nexus, than to have it be externalized to taxpayers generally. The point would be the same-though the opposite conclusion would be drawn-if faulty drivers generally were judgment-proof and injured victims of judgment-proof drivers were compensated from general tax revenues. The issue of whether pedestrian-auto accidents are most cheaply avoided by charging faulty drivers or nonfaulty pedestrians would on this hypothesis ignore the real issue-namely, would they be more cheaply avoided by charging taxpayers generally or nonfaulty pedestrians? These hypotheses, of course, are not meant to represent the real world. They are meant to point out that the fault system is not very likely to pick the cheapest cost avoider because it never looks beyond the particular accident to who really pays.

The same concentration on the particular makes the fault system ignore the danger of externalization by insufficient subcategorization. ${ }^{18}$ At first blush this may seem strange-for what greater subcategorization can there be than to choose the individual driver or pedestrian in the particular accident? It may not be worth the cost to subcategorize that far, but surely the fault system cannot be faulted for failure to subcategorize. Unfortunately, the facts of accident cost allocation are such that the fault system, while incurring massive administrative costs in order to subcategorize to the last degree, ends up failing to subcategorize adequately. This failure is really a product of externalization by transfer and by inadequate knowledge.

The fault system might be thought to seek the cheapest cost avoider in each accident instance. ${ }^{19}$ The particular driver or pedestrian held liable ${ }^{20}$ would seem to be the smallest subcategory of driving or walking possible. The theory is that by holding the smallest subcategory liable one builds up relevant larger categories which bear their appropriate costs. Thus if twenty-five and thirty-five-year-old drivers had equal accident propensities, it would not matter, except in terms of administrative costs, that we bothered to differentiate them into separate subcategories. The sum of the cases would show an equal burden on both subcategories, and the allocation by age would have been harmless. If instead it turned

\footnotetext{
${ }^{18}$ But sec, The Empty Cabinet, supra note II, at 244 .

${ }^{19}$ In fact, the fault system probably does not even seek the cheapest cost avoider ainong the litigants in each particular accident situation. If nothing else, the intentional introduction of moral judgments into the liability decision should suffice to make inaccurate any such simplified statement of what the fault system attempts to do. If, despite this, we evaluate the fault system as a market control system, the best that can be said for it is that it might be trying to identify the cheapest cost avoider among the litigants. Cf. Public Law Perspectives, sipra note $I \mathrm{I}$, at 63,69 .

${ }^{20}$ Throughout this article I use the term "held liable" in a rather peculiar way. As in previous articles,

"I am using the term to identify the party who under the law bears the initial undivided loss, whether that party is the party who is originally injured or the party who through a legal judgment must compensate the injured party and thereby becomes the financially injured party. I use the term this way to emphasize the fact that whether the originally injured party or some other party is made to bear the undivided loss, in the first instance, is the result of a legal judgment, a 'holding liable,' and not of metaphysics."

The Wonderful World, supra note 2, at n.23.
} 
out that they had different accident records, the difference would be reflected in the sum of accident costs charged to each, and a potentially significant subcategory difference would have been made.

The problem is that categories are not built up that way-they are built up on the basis of insurance companies' estimates of what are relevant differences and how expensive it is to recognize them. Since walking is not an organized activity, it may be far more expensive to sell insurance by category of walker than by category of driver. As a result, allocation of a particular accident cost to a faulty pedestrian in the belief that this will result in distinguishing out a subcategory of pedestrians who are particularly accident-prone may be doomed to failure. The costs of establishing such a subcategory may be great enough so that the result of this allocation is to place the cost on "pedestrianism" generally or, even more likely, on "living" generally (through general accident insurance). This might be a less adequate subcategorization than if the nonfaulty driver had been held liable, since the costs of insurance categorization for driving might be such that this allocation would result in burdening that subcategory of drivers who are most likely to hit pedestrians. The point is simply this-the fault system's concentration on whether the particular pedestrian or driver could avoid the accident most cheaply ignores the fact that because of insurance neither will in fact bear the accident costs. And the breadth of the insurance categories which in fact will bear the costs, and therefore affect behavior, depends not only on the difference in accident-cost-causing potential of the members of the category but also on the cost of differentiating these members into subcategories and selling insurance to such differentiated groups. If what we are looking for, in other words, is the feasible insurance category which can avoid the accident costs most cheaply (which subcategorizes as much as possible) we do far better to look for that directly rather than to look for a totally hypothetical individual "cheapest cost avoider" and hope that charging him will result in the best insurance category possible.

It may be said, however, that this is simply a bad effect of insurance and that the fault system would successfully subcategorize if insurance were forbidden. Then, it might be claimed, each individual would bear his own losses and the greatest degree of subcategorization possible would be achieved. But this is not what would happen. Just as externalization by transfer (through insurance) causes the fault system's case-by-case allocation of accident costs to result in broader categories than are necessary, so externalization by lack of adequate knowledge causes the same thing, absent insurance. Absent insurance, allocation of accident costs to individuals involved in specific accidents affects behavior only to the extent other individuals correctly identify themselves with those who are charged with the costs. To the extent that individuals fail to appreciate adequately the risk of an accident cost burden falling on them, the cost allocation will fail in its objective. Similarly, to the extent that individuals overestimate the risk to themselves, they will overreact 
to the cost allocation. Moreover, if individuals associate the risk with a broader activity than that which actually would bear the cost if there were insurance, they may well abstain from a broader activity than they should, and once again inadequate subcategorization will have resulted.

Assume pedestrian-auto accidents occur mainly to young drivers driving at night. Allocation of the costs to these, insurance being forbidden, may well result in externalization (even assuming that they are not judgment-proof). If young drivers who drive at night systematically underestimate the risk of such accidents, they will not modify their behavior. If old drivers overestimate the risk, they may unnecessarily (and uselessly) stop driving at night. Even worse, they may stop driving altogether because they do not realize the extent to which the risk is night-associated. In all cases, the appropriate subcategory would not be affected. ${ }^{21}$ Clearly, prohibition of insurance would not make the fault system an adequate system for internalizing costs. ${ }^{22}$

The whole discussion of externalization can be summarized in the following way. It may be that the fault system seeks to allocate accident costs to the individual party to an accident who could have avoided the accident costs most cheaply. But such individual allocation fails to find the true cheapest cost avoider, because the individual who is picked often will not bear the costs charged to him, and even in those cases where he does bear the costs there is substantial danger that the allocation will not affect those who are, in fact, prone to the same accident costs as he. The costs will in all these cases be externalized to other groups of people. Rather than centering on the individual, a system designed to find the cheapest cost avoider should therefore look to the groups which will in fact bear the loss. By doing this the system maximizes the chances of charging costs to the group which can avoid them most cheaply. It is useless to charge a pedestrian with the costs of auto-pedestrian accidents, even though in theory he could avoid them more cheaply than the driver, if the effect of charging him is that income taxes go up by an infinitesimal amount and injured pedestrians are compensated from the general coffers. It would be appropriate instead to consider whether the category of drivers which would bear this loss if it were allocated to the driver could avoid the accident more cheaply than could the state. They, not the individual litigants,

\footnotetext{
${ }^{21}$ An equally undesirable result would occur even' if drivers accurately estimate the risk of accidents, but give that risk a greater value than they would if they could insure against it. This would happen if they believed-probably quite properly-that an unspread burden would hurt them more than a spread burden. In this situation, the prohibition of insurance would cause a larger than optimal burden to be placed on the activity.

22 This discussion leaves out other reasons why prohibiting insurance may result in externalization. If the result of barring insurance is that too many people are crushed by unspread accident burdens, the demand is likely to arise for some government compensation scheme. Such a compensation scheme, if paid out of general taxes, wouid have the effect of externalizing the cost of accidents from the people beld liable to taxpayers generally. Even with insurance, demands for this kind of political externalization by transfer are great under the fault system. Without insurance the demands would likely be overwhelming.
} 
would in my example be the "cost avoiders" among whom we must identify the cheapest.

If the fault system does a poor job of keeping accident costs from being externalized for any given level of administrative costs, it does a terrible job of achieving an optimal relationship between avoidance costs and administrative costs. The most expensive aspect of the fault system is its case-by-case jury determination of who should bear losses. And yet as we have seen in the discussion of externalization, it is precisely that case-by-case approach which seems to lead to unnecessary externalization. Perhaps this is not a necessary result. Perhaps one could devise a system of case-by-case allocation of costs which could consider the factors relevant to externalization. But at best this would be a harmless though costly exercise, walking up the hill simply to walk down again. If the aim is to find the cheapest cost avoider categories, the burden must surely rest on case-by-case allocation of costs to prove that it adds something worthwhile. So far that has not been shown. I do not mean by this that records of individual cases ought not to be kept and used to decide what categories are relevant. I mean that the fault system's method of allocating damages is an awfully expensive way to build up a statistic, quite apart from the fact that the statistic so developed is likely to be misleading. We have already seen why it is misleading to the extent that it ignores externalization. As we shall soon see, such a case-by-case attempt to find cheapest costs avoiders is in fact misleading for other reasons as well. For now it is enough to say that it is a very expensive way of being misled.

Besides requiring what may be unnecessary administrative costs of case-by-case determination, the fault system fails to achieve an optimal level of administrative costs for another reason. It fails to consider in allocating accident costs which of the parties is the cheapest "spreader" or insurance buyer. I am not here concerned with the failure of the fault system to spread accident costs adequately from society's point of view-I have expressly left that out of this article. I am here concerned with its failure to give weight to the fact that it costs different amounts for different parties to an accident to spread the accident costs, even though they may be equally prone to that particular accident. The effect of allocating costs to parties who can spread only by paying relatively high insurance premiums is that unnecessary costs of spreading are introduced into the system. These unnecessary costs of spreading can only be avoided by failing to insure. But then an unnecessary burden of unspread accidents costs is introduced. Either way we have chosen an inefficient system.

This problem only arises because of the existence of transaction costs. Absent such costs, parties having equal risk of accidents would always face equal premiums. With transaction costs this is often not true. Again industrial accidents may be a good example. It may well have been true that workers could only get insurance for themselves at relatively high rates, whether they went to insurance companies 
or made individual contracts with employers to indemnify them. Employers instead, if held initially liable, could insure against precisely the same risks-indeed the same accidents-far more cheaply. Yet the fault system deemed this irrelevant to liability.

This weakness of the fault system, as we have seen, has an important connection with externalization. If the desire to spread accident costs is sufficiently great, and if the cost of insurance to one party is sufficiently high, the result of holding that party responsible may be to cause him to insure anyway but at a very broad category level where insurance can be obtained more cheaply. The effect of this would be to avoid the unnecessary spreading cost; but at the price of incurring less adequate accident cost avoidance because of externalization. In essence, this is what was involved in the example of the fault system's externalization by inadequate subcategorization.

If drivers and pedestrians were equally good avoiders of pedestrian-auto accident costs, but insurance against such accidents were much more expensive for pedestrians than for drivers (since walking is not an organized activity), making the pedestrian liable would present the following choices: $(x)$ The pedestrian might not insure (but this would leave society bearing the cost of unspread accident costs, and externalization by inadequate knowledge might occur besides). (2) The pedestrian might buy pedestrianism insurance (but this would accomplish the desired accident cost avoidance at an unnecessary cost because, by hypothesis, an equally good accident cost avoider, the driver, could buy insurance at lower rates). (3) The pedestrian might find it cheapest to buy insurance which covered all accidents (spreading would be accomplished, but the cost of pedestrian-auto accidents would have been made a cost of living generally and not kept on either of the two subcategories of living which could avoid the accident costs cheaply, driving and walking). Each of these results would be less desirable than that which would occur if the cost were placed on driving originally. Indeed, if drivers were slightly less cheap accident cost avoiders than pedestrians (because all drivers were free from fault and all pedestrians were somewhat faulty), the same result might still hold true. The choices facing pedestrians would be the same: Both pedestrian noninsurance and pedestrian insurance might still cost society so much as to be less desirable than driver insurance, even though drivers could only avoid the accidents somewhat less cheaply than pedestrians. And externalization of the cost by pedestrians to living in general through comprehensive accident insurance would surely be less desirable than driver insurance, because drivers could avoid auto-pedestrian accidents more cheaply than could citizens in general. ${ }^{23}$

\footnotetext{
${ }^{23}$ This general weakness of the fault system may come about simply because the fault system, in ignoring who can insure most cheaply, seeks the cheapest cost avoider among the litigants in an incomplete way. It may seek the cheapest avoider of primary costs. But by ignoring which of the litigants is the cheapest avoider of secondary costs, it may burden a litigant who is not the cheapest
} 
The fault system does not even purport to take into account the third criterion I outlined for finding the cheapest cost avoider: when we are unsure who the cheapest cost avoider is, we should allocate the cost so that the market has the greatest chance of correcting an error if one is made. This amounts to the following injunction: when in doubt, allocate the cost to the party who can most cheaply enter into transactions to rectify an error. There is no point in discussing this criterion at length. The manner in which transactions can be entered into to rectify allocation errors has been discussed in Professor Coase's celebrated article, ${ }^{24}$ and I have tried to expand on Coase's analysis in a recent article. ${ }^{25}$ The thrust of the argument can be readily shown by an example. Suppose the location of a factory near a residential area results in a smoke pollution problem. Suppose also that there are two possible methods of reducing the costs of pollution substantially. The first involves the factory building a higher smokestack with a smoke control device on it. The second consists of homeowners installing a new type of glass in their windows. Suppose finally the unlikely, that we do not know which of the two methods would avoid the cost of pollution most cheaply. If it costs nothing for either party to pay to induce the other to change his behavior, the market would always find and establish the cheaper method. But such subsidization does cost money, and, since it is almost certainly cheaper for the factory to subsidize homeowners than it is for homeowners to unite to subsidize the factory, liability of the factory would be justified. This is not because we know which method of cost avoidance is cheapest but because by making the factory liable we have diminished the obstacles to corrective market action. The contrast between this approach and that of the fault system is manifest. If there is "fault" the allocation would be placed on the faulty party, regardless of how doubtful it may be that the existence of fault makes that party the cheapest cost avoider, and regardless of which party can most cheaply bargain with the other to correct an error. If there is no fault, the fault system (which should not care who bears the loss) lets it lie where it falls, and makes no attempt to charge the party which can find the cheapest cost avoider most cheaply. My example is an overly simple one-and its very simplicity may help explain why the fault system is not really used in the area of factory pollution problems-but this does not alter the fact that the failure of the fault system to concern itself with the question of finding the best "subsidizer" suggests pretty strongly that the fault system is not, by any means, a good system of market control of accidents.

The discussion of these three criteria leads us to what is perhaps the most important single requirement for picking the cheapest cost avoider: $A$ forum and method must be chosen which is most suited for taking the previous criteria into

avoider of the sum of primary and secondary costs. And this ultimately results in unnecessary costs being borne.

\&4 Coase, supra note 12.

${ }^{25}$ Transaction Costs, supra note 12. 
account and which can most easily examine which party can most cheaply modify its behavior so as to avoid accidents. In other words, we must entrust the choice of cheapest cost avoider to a forum which is capable of (a) ruling out all those activities which by a kind of rough guess we would readily agree cannot be the cheapest cost avoiders of a category of accidents; $(b)$ considering which allocation leads to maximum internalization at any given administrative level; $(c)$ ruling out allocations which cost more to bring about than they are worth; $(d)$ identifying the cheapest subsidizer among loss bearers who remain possible; (e) making the best intuitive guess of what activity is likely to be the cheapest cost avoider, to the extent the previous criteria do not conclude the issue; and $(f)$ doing all this without introducing other, extraneous factors. ${ }^{26}$

The fault system uses a jury, a case-by-case allocation of losses, and adopts a series of limitations (like "all-or-nothing damages" and "no recovery if neither party is at fault"). It also encourages the introduction of moral factors in the decision. Leaving the last point aside-for that obviously suggests that the fault system is meant to be a mixed system of accident control rather than a market system, and I am not yet discussing how good a mixed system it is--I think both the forum chosen and the limitations which fault imposes on itself make selection of the cheapest cost avoider far less likely than is needed.

The first point is that a case-by-case determination of who ought to bear losses is not particularly desirable if the object is to find the cheapest cost avoider. We have already seen that case-by-case decisions $(a)$ make it difficult to take externalization into account, $(b)$ make it difficult to consider what category can subsidize most easily, and $(c)$ entail substantial administrative expense. There are, however, other reasons why case-by-case determinations are likely to be misleading in finding the cheapest cost avoider. The effect of case-by-case decisions is to center on the particular or extraordinary cause of an accident. If one asks, as case-by-case determinations tend to do, "what went wrong in this case?," the answer one is likely to get will center on the peculiar cause. Yet there is a very good argument for the notion that the cheapest way of avoiding accident costs is not attempting to control the "unusual" event but rather modifying a recurring event. It may be that absentmindedness is a cause of a particular accident, and too much whisky of another, and drowsiness of a third-but it may also be that a badly designed curve or inadequate tires are causes of each of these as well. The fault system, because it centers on the possible particular cost avoider, is very likely to ignore the recurring cost avoider and hence fail to consider some potential cheapest cost avoiders-like highway builders or tire makers-altogether.

\footnotetext{
${ }^{20}$ A typical extraneous factor would be collective moral judgments as to the desirability of the activities involved. This factor is extraneous to finding the cheapest cost avoider if we are secking a predominantly market system of accident cost control. If we want a mixed system it may not be extraneous, and the question becomes: is the forum used the forum best suited to introduce collective moral judgments into the system?
} 
This weakness is compounded by the fact that concentration on particular accidents inevitably means concentration on accident avoidance. What we should be concerned with instead, in terms of market control, is accident cost avoidance. It may be very expensive to avoid many car accidents altogether, and yet their costs could be reduced substantially by designing cars differently. A system which assessed liability to varying activities on the basis of broad accident cost statistics derived from individual cases, and did not seek to determine a single liable party in each case, would be much more likely than the fault system to give accident cost avoidance the importance it deserves.

Concentration on general or recurring causes of accidents might, of course, result in overlooking some very cheaply avoided particular causes of very high accident costs. But this does not seem as likely as the reverse error, especially since the statistics on which allocations of liability to different activities would be based would continue to be compiled from investigation of particular cases. ${ }^{27}$

When the tendency of case-by-case jury decisions to miss relevant cost avoiders is added to the already discussed disadvantages of case-by-case determinations, it becomes pretty clear that a system which sought to allocate accident costs so as to maximize the degree of market control would not use case-by-case determinations. If this is so, use of jury case-by-case decisions in the fault system must find whatever justification it may have in aims unrelated to market control of accidents. To put the same thing slightly differently, a system which sought to accomplish a high degree of market control of accidents could, in theory, use a jury and case-by-case

${ }^{37}$ Such a method of compiling statistics-though costly-is bound to be cheaper than the fault system's case-by-case allocation of losses. The reason for this is that the description of what happened, which the parties would give in a compilation of statistics method, can more readily be accepted on its face than the description of the same events which the parties to a tort action would give. This would be especially true if the description given for purposes of statistics were immune from subsequent use in criminal cases. The point is that in the fault system the victim has every reason to lie, or at least exaggerate, in order to establish the injurer's fault. This would not be so in compiling statistics if compensation did not depend on the facts of the particular case and the statistics merely affected what categories of activities paid what amounts into the fund from which compensation would be sought. Cf. Franklin, Replacing the Negligence Lottery: Compensation and Selective Reimbursement, 53 U. VA. L. REv. 774, 798-802 (I967).

At first glance, it might appear that this lack of incentive to exaggerate would already be the case with the insured injurer under the fault system. After all, he has already paid his premiums-so why should he lie about what happened. (Cf. the discussion at p. 456 infra on why this makes the fault system an inadequate system for collective control, and at pp. $443-44$ supra on why the fact that victims are not generally insured is not enough to put adequate pressure on possible victims.) But this conclusion ignores both the requirements of the insurance contract and the psychology of litigants. Insurance contracts normally require, on pain of nonpayment of liability, that the insured co-operate with the company in defending any suit. This is not meant to encourage exaggeration or misstatements on the part of the injurer, but it certainly puts him in the position of an adversary to the victim, and unreliability of the statements he makes follows as a matter of course. The effect is compounded by the fact of litigation. However little pressure to act safely the injurer may have felt before the accident, because he was insured, once litigation is started he feels that, at least in part, he is on trial and that a verdict of liability impugns his behavior. Again the unreliability of his statements follows. A very different attitude and considerably greater reliability seems likely if, after each accident, facts are gathered for the purpose of deciding which category of activities will pay what into a general compensation fund. 
decisions, but it is pretty clear that use of such a forum and method would be both wasteful and inaccurate in terms of that system's avowed goal.

The second point dealing with the method the fault system uses to allocate losses goes to the limitations the fault system imposes on itself. These are primarily (a) little or no quantitative division of damages, (b) little or no qualitative division of damages, and $(c)$ allocation to the victim where no fault is found. These limitations are perhaps not as crucial to the fault system as is case-by-case decision; they could be modified and the system still remain essentially a fault system. ${ }^{28}$ At the moment, however, they are very much a part of the fault system, and they certainly hamper the search for the cheapest cost avoider.

The fault system normally does not divide damages among involved partics. In terms of market control of accident costs, this implies that in every accident the cheapest way of avoiding costs involves altering the behavior of only one party. But this is clearly not the case. Often the cheapest way of avoiding accident costs is for several parties or activities to alter their behavior somewhat. The cheapest way of avoiding pedestrian-auto accident costs may be for cars to use spongy bumpers and for pedestrians to wear white fluorescent buttons rather than either to have cars adopt pedestrian-spotting radar or to have pedestrians wear armorplated underwear. If this were true, an allocation of accident costs which divided the costs between drivers and pedestrians would be better than one which charged all costs to either group. I do not argue that this will always be the case. I do not even argue here that, absent any indication as to who in fact is the cheapest cost avoider, a division of costs is better than a lumping of all costs on one party (although I have so argued elsewhere and although there are some reasons for believing this to be true $\left.{ }^{29}\right)$. I merely argue that a system which, at least in theory, excludes division of damages is limiting itself unnecessarily in looking for the cheapest way of avoiding accident costs, because sometimes the cheapest way requires dividing accident costs among several parties.

Even more significant than quantitative division of damages, in terms of cheap accident cost avoidance, is qualitative division of damages. The activity which can most cheaply avoid certain types of costs is often not the activity which can most cheaply avoid others. The fault system has to some extent struggled with this problem.

\footnotetext{
${ }^{28}$ A general shift to comparative negligence is, of course, the most obvious example. Greater enphasis than is now allowed on which individual litigant could control which types of damages most easily would be another. A shift to a division of damages on some nonfault basis where neither party is at fault would be a bigger change. But of. Larsen v. General Motors Corp., 39r F.2d 495, 503-04 (8th Cir. 1968).

${ }^{29}$ See, The Decision for Accidents, stipra note 3, at 739-42. According to probability thcory, abscnt indications as to who is the cheapest cost avoider, dividing accident costs equally among the activitics involved in each accident will maximize the chances of achieving cheapest cost avoidance, assuming that as the deviance between the actual allocation and the best possible allocation of costs increases, the costs of the misallocation increase at a faster rate. This seems a reasonably valid assumption in vicw of the way demand and supply curves are normally considered to be shaped. Contrast Blum and Kalven's treatment of the same issue in Public LAw Perspectives, stupra note II, at 68-69.
} 
Rules requiring victims to take steps to mitigate damages once they have occurred can be viewed as halting steps in this direction. So can the occasional cases allocating to victims damages which are totally atypical of the risk because of which the injurer was deemed at fault. But certainly the fault system does not make qualitative divisions of damages according to ease of cost avoidance as a matter of course. Typically pain and suffering follow physical and economic damage. Typically also, the exceptional value of a hand to a great violinist is assessed to a faulty injurer because "one takes one's victim as one finds him." Yet there are good arguments to be made that in whole categories of cases (e.g., industrial accidents, auto-pedestrian accidents) the injurer is the likely cheapest cost avoider with respect to normal physical and economic costs, while the victim may be the cheapest cost avoider as to pain and suffering and highly individualized economic damage (like the violinist's hand). These arguments are far from conclusive, and in all events the issue is far too complex to be resolved here. It is enough to say that the fault system seems oblivious even to the possible relevance of widespread qualitative division of accident costs. It must therefore fail with unnecessary frequency to allocate costs in a way which would maximize the chances of causing their cheapest possible avoidance.

The last, and perhaps most important, self-imposed limitation of the fault system is the rule that, absent fault, costs remain where they fall. Holmes gave the best justification for this rule. He wrote that where no benefit accrues to society from shifting a loss, there is no reason to incur the administrative costs of shifting it. $^{30}$ That statement is unexceptional in itself, but as applied to the faultless accident it contains premises which are invalid.

First, it assumes that by failing to shift the loss in faultless accidents administrative costs are saved. This is only true if the distinction between faultless and faulty accidents is so clear that, on the one hand, a great number of costly attempts to shift losses are precluded by the rule and, on the other, those losses which are shifted in spite of the rule do not cost substantially more to shift because of the existence of the rule. A little thought on how the fault system operates today should suggest that this is a dubious assumption. How often do people fail to sue because "absence of fault" is obvious? How much more expensive than it need be is accident litigation because fault is an issue in each particular case?

Second, Holmes's statement also requires that no societal benefit accrue from a shifting of the loss. He did not, of course, consider spreading as a possible societal benefit and for the purposes of this article neither do I. But is it so clear that absent fault there is no reason (other than spreading) to shift some accident losses? Is it clear, in other words, that absent fault on one party the search for the cheapest cost avoider would be totally indifferent as to who bore the loss? I think enough has been said to suggest that in fact the opposite is true-and the

\footnotetext{
${ }^{30}$ See O.W. Holmes, The Coman Law, 76-77 (Howe ed. 1963).
} 
absence of fault by no means guarantees the absence of a findable allocation which will burden the cheapest cost avoider and thereby maximize market control of accidents, minimizing the sum of costs of accidents and of their avoidance.

Most obviously, if, in the absence of indications that one party is a cheaper cost avoider than the other, an even split maximizes the chances of allocating costs to the cheapest cost avoider, letting costs lie where they fall is bound to be wrong. ${ }^{\mathfrak{1}}$ In addition, one party may be a better subsidizer than the other, where neither is at fault. As we have seen, other things being equal, allocation of costs to the best subsidizer maximizes the chances of optimal market control of accident costs. Finally, even if we assume that absence of fault means that each of the individual parties to the accident is precisely equal in terms of ease of accident cost avoidance, the possibility of externalization might make one party a far better loss bearer than the other. Once again, the fault system by concentrating on the individual parties and finding which bears the loss to be a matter of indifference (in terms of fault, or even in terms of cost avoidance) fails to look to who really pays and, therefore, fails to consider whether at that level indifference still exists. A pedestrian and a driver involved in an accident may be faultless, and we may therefore think we are indifferent as to which of the two pays. But allocation of the loss to the pedestrian may result in the cost becoming a general cost of living while allocation to the driver may make it a cost of driving by a particularly accident-prone group. If these two allocations are compared we may find that we are no longer indifferent.

There are, in fact, other, quite complex reasons why a cheapest cost avoider can often be found even between two faultless parties, even defining fault in terms of its best definition (Learned Hand's classic negligence calculus ${ }^{32}$ ), and even leaving out externalization, best subsidizer, and so on. These go to the relevance of foreseeability in the negligence calculus and the effect of moral elements on the negligence calculus. But they would take too long to outline here, and they are not necessary to make the point that a system which sought to burden the cheapest cost avoider would often shift losses even in the absence of fault. Indeed, the best answer to Holmes is that there are many areas in tort law today where the shifting of losses in the absence of fault has clearly resulted in a reduction of the sum of the costs of accidents and of their avoidance and therefore in a benefit to socicty quite apart from the possible benefits arising from the spreading of losses. ${ }^{83}$

\footnotetext{
s1 See note 29 supra.

${ }^{32}$ See, e.g., Conway v. O'Brien, III F.2d 6II, 6r2 (2d Cir. I940), rev'd on other grounds, 312 U.S. 492 (I94I).

ss The effect on the development of safety devices of workmen's compensation and strict liability for ultrahazardous activities are two obvious examples. Another example might be the use of assumption of risk (in those few situations where the doctrine is used properly) to deter certain kinds of "ultrahazardous" plaintiff activity by denying liability where the behavior of the plaintiff was in no sense faulty, but where he (or the category to which he belonged) could, in fact, avoid the accident costs most cheaply, because he knew the risks involved as well as anyone and could avoid them more cheaply than anyone else.
} 
III

Thus far in this article I have attempted to establish that the fault system is not the system we would use if our goal were the establishment of an optimal system of market control of accident costs. I have tried to show that if our aim is to allocate accident costs to the party, category, or activity which can best make the choice between avoiding and incurring accident costs and thereby bring about the minimization of the sum of costs of avoiding accidents and costs of having accidents, we would not allocate costs on the basis of fault. I have tried to show that the fault system is a poor system of market control even without regard to the fact that it decides who should bear losses partly on the basis of moral considerations which are antithetic to pure market control of accident costs.

It can be argued, however, that the fault system has no such market control aims in mind, that the very fact that it allows moral elements suggests that it is a far different system and must be judged on a different basis-namely, how good a system of collective control of accidents it is. I would agree, but only in part. Some of the arguments recently made in favor of fault are quite unclear on the issue. Indeed, at times Blum and Kalven, for instance, have written as if the perfect justification for the fault system was its efficacy as a system of market control of accidents. ${ }^{34}$ Elsewhere in the same pieces, however, they write as if its justification is to be found in the purity of the justice it doles out (a purity I fail to see but have in any case excluded from discussion in this piece), and finally they seem to defend fault at times in terms of its effectiveness as a system of collective control..$^{35}$ I have argued that fault must be judged on all these bases, that it, like all real systems, is a mixed system which combines all these goals. Accordingly, I shall now turn to how successful the fault system is as a system of collective control of accidents and then proceed to an evaluation of how well it mixes market and collective elements.

The crucial difference between market deterrence and collective deterrence is that in market deterrence we let individuals decide whether an act or activity is worth doing given its cost to society, while in collective deterrence we decide collectively for individuals whether the act or activity is worth its cost to society and should be allowed. It is easy enough to show that there is nothing that the fault system does by way of collective deterrence which could not be done more effectively by a system of rules and regulations enforced by appropriate penalties ranging from criminal nonmonetary penalties-such as jail-to civil monetary ones such as noninsurable tort fines.

Often, however, we want more than simple collective deterrence. We may decide that we want no more than a set number of cars on the highway, because collectively (whatever individuals may believe) we do not think more cars than that

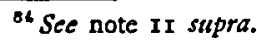

${ }^{20}$ See, The Empty Cabinet, supra note II, at 255-56, 268-72; Public Law Perspectives, supra note II, at $12,83-84$.
} 
number are worth their costs. We may not care, however, who drives so long as the total number of cars is limited. To the extent that we do care who drives the limited number of cars, we are still in the range of simple or pure collective deterrence. For then we not only decide collectively that so many cars and no more are desirable, but we also decide collectively that the most desirable drivers for such cars are specific people, say drivers between twenty-five and sixty, regardless of how much an individual sixty-five-year-old or an individual fifty-year-old thinks driving is worth to him. If instead we simply decide the total number of cars desired collectively but let individuals choose (either according to willingness to pay or some other market device) who can drive the limited number of cars, we are using a system that involves both collective and market controls. ${ }^{36}$ We may put a large enough tax burden on cars so that only the collectively desired number are purchased, but the choice of who purchases them remains a market choice. I call this imperfect collective deterrence "limitation" of an activity; the purer form of collective deterrence I call "restriction" because it restricts the activity to a collectively selected group. ${ }^{37}$ Unfortunately for the fault system, it can be shown that where limitation of an activity is the extent of collective deterrence desired, devices like taxation (combined with allocation of accident costs to maximize market control) are more effective than the fault system. But more on this later; at the moment we must look at fault and pure collective deterrence.

To see why the fault system is inefficient as a system of pure collective control, we must first consider the two principal situations which most often seem to justify collective control. The most obvious one is where the act or activity involved has sufficient moral connotations so that we are unwilling to let individuals decide for themselves whether the cost of the act to society is worth paying. In such

\footnotetext{
${ }^{36}$ An interesting contrast to both of these methods is the case where the people picked for the "limited" activity are chosen by lot. Choosing by lot suggests that while we do not have (or do not wish to exercise) collective preferences as to who should engage in the activity, we cannot (for rather special reasons) tolerate a market choice of who should take part. The arguments concerning a draft lottery in time of war illustrate the situations where this may be the case. Doubts about how collective decisions are made and how income distribution affects market decisions suggest, to some pcople at least, that a totally arbitrary choice (like a lottery) is more desirable where lives are so obviously at stake. How people are selected for special medical treatment not yet generally available (like kidncy dialysis and heart transplants) affords an example of the different approaches taken in different hospitals to a similar problem.

${ }^{37}$ The same analysis, in reverse, applies where particular activities are collectively deemed to be especially desirable. Home ownership is an example. A general subsidy to the building industry or to the mortgage industry might be given. This would presumably lessen the price of home ownership and, therefore, increase the number of people who would buy houses. The market, however, would determine which individuals bought the now greater available number of homes. The result is analogous to a limitation of an activity. If, instead, an increase in home ownership by particular groups was collectively decided upon, the subsidy would be made available only if the members of the particular groups applied for a house. This is analogous to a restriction of an activity. Cheap mortgages for veterans is an obvious past use of such a subsidy restricted to a particlular group. Even more closely analogous to a restriction would be the case where each person in a particular group were given a free house (or education) regardless of how much he desired it.
} 
cases it is irrelevant whether or not the origin of our moral attitude rests in long past evaluations of the cost of the act. The crucial point is that as of now individual decisions are not desired. Murder is an obvious example. Suicide is another.

The second major area where collective control is desired is one where cost rather than morals is the basic element but collective controls are more efficient than market controls. Early in this article I suggested that it was inefficient to try to decide everything collectively. The reverse is also true. It is often enormously expensive to put the cost of certain closely defined activities (what we usually call "acts") on individuals in such a way that they can choose whether or not the act is worth doing given its cost. If we can be reasonably sure that most individuals, if given the choice between abstaining from the act and paying its costs, would abstain from the act, we are usually justified in barring the act altogether. The savings in administrative costs resulting from using collective controls would usually outweigh the loss to those few who, if allowed to, would pay for the right to do the act. ${ }^{38}$ In both these situations it can be shown that uninsurable penalties are far more effective than the fault system.

What are accident situations where moral connotations are important? They must all be situations where individuals can know before the accident and at a time when they can still control their behavior that the acts or activities they desire to do are considered wrong, or faulty, regardless of whether an accident occurs. This follows from the meaning of the word moral. Such wrongful acts or activities cannot always be described precisely before a specific event such as an accident. But they must at least be sufficiently describable so that a normal individual can, if he wants to, give the description meaning in terms of the particular situation in which he finds himself.

Consider, for example, the distinction between drunken driving and careless driving. Drunken driving is an activity which can be described sufficiently well so that individuals can know what is deemed wrongful and abstain from it, totally apart from accidents. Careless driving is another matter. It too may be deemed wrongful, but we would be hard put to give it an abstract all-inclusive definition. Still, we might be correct in terming it wrongful if individuals can give specific meaning to our general notions of what careless driving is in most real contexts in which they find themselves. But we would only be correct in calling it wrongful-even in terms of the fault system's definitions-if individuals could give it meaning in time to avoid acting in the condemned way. This fact is crucial to the fault system's ineffectiveness as a system of collective control. ${ }^{39}$

\footnotetext{
${ }^{3 a}$ Cf. Transaction Costs, sulpra note 12 , at $69-73$.

${ }^{30}$ It should be re-emphasized that when I speak of the fault system $I$ am speaking of civil liability in torts. I am not considering as part of the system the plethora of criminal penalties which we also use to control certain kinds of undesirable behavior. Obviously these penalties attempt to accomplish, in part, what I am suggesting a system of collective control would seek to accomplish. They are preciscly there to enforce collective rules. The reason I do not consider them as part of the fault system
} 
It should be readily obvious that whenever we are dealing with activities like drunken driving which can be defined and found apart from accident situations, a system of appropriately sized noninsurable penalties is more likely to be an effective deterrent than the fault system, which allows a substantial part of the penalty to be both shifted and prepaid through insurance. The effectiveness of the collective deterrent remains greater if the drunken driver must bear the penalty himself and if he faces the prospect of the full penalty at the time he chooses to drink and drive. Collective deterrence would in theory fine drunken drivers regardless of accidents. But noninsurable penalties remain more effective than the fault system even if in most cases drunken drivers are caught only if they have an accident. Indeed, the sole reason for usually catching drunken drivers only if they have an accident is one of economy. It costs too much to check if all drivers are sober, so we penalize drunken drivers only when an event calls their drunkenness to our attention. The event of the accident calls the wrongful act to our attention, and we therefore assess the penalty.

The case of careless driving is similar, but with respect to it there is even more reason for bringing collective controls to bear only where an accident has occurred. It is often impossible to define the careless act or activity except in the context of a potential accident situation. It therefore is even more expensive, indeed impossible, to catch and penalize some types of careless driving except when an accident occurs. We would have to have an all-seeing policeman riding in every car for it to be otherwise. But the fact that much careless driving can only be caught after an accident occurs does not alter the basic fact that we would not call it wrongful unless we believed that the driver could judge that what he was doing was improper soon enough to avoid doing it. Whenever this is so, whenever normal individuals can choose whether to engage in wrongful conduct before an accident, an appropriately sized noninsurable penalty is necessarily a more effective deterrent than an already paid insurance premium.

I have emphasized "appropriately sized" for several reasons. First, we may not always be correct in gauging whether the conduct was wrongful-that is, whether the individual could identify it as such and abstain from it before an accident. Too large a fine or a criminal penalty in an area where errors are likely may result in individuals abstaining from conduct we do not deem wrongful, like driving in general, for fear that if they drive at all they may occasionally be wrongly found to do a wrongful act and wrongly penalized. Too small a penalty will simply be taken as an invitation to take a chance. These difficulties are, of course, unavoid-

is that the very question I am asking in this section of the article is: what does insurable civil liability based on fault (i.e., the fault system) add in the way of collective control which an expanded system of noninsurable penalties would not do better? In previous parts of the article I have, in effect, considered whether the fault system adds effective market control to these existing criminal penaltics. In the section yet to come, I shall consider whether insurable civil liability based on fault is a better mixture than an expanded system of noninsurable penalties and an optimal system of market control. 
able, but they do not alter the fact that a rational system of fines and penalties is bound to be more effective in dealing with this type of conduct than insured-against fault payments, in which the only deterrent that can be effective, at the time the choice between doing and not doing a wrongful act is made, is the possibility of higher premiums in the future (a possibility which exists even if an accident is not due to the insured's wrongful act). ${ }^{40}$

One may well ask whether there is not a category of acts or activities which can be deemed wrongful only after an accident has taken place, or at least after it is too late for the actor to avoid doing the act which after the accident is deemed to have been wrongful? And if there is such a category, whether this is not precisely the category which the fault system attempts to deter collectively? A complete exposition of the answer to this is too complex for this article. The short answer is "no, there is no such category," and even if there were, the rubric of the fault system (foreseeability, etc.) would seem to make fault irrelevant to such a category. There may be acts which after an accident we can all agree were undesirable-that is, we wish had not happened. But as to such acts, since they can only be deemed undesirable after it is too late for anyone to choose to avoid them, the only control system we can want is either a market control system which lessens the attractiveness of the activities in which these ex post undesirable acts occur most frequently, or a collective control system which limits, restricts, or forbids the activities in which these acts are liable to occur. As to the first alternative, a market control system is preferable to the fault system for all the reasons given in my discussion of market controls. As to the second, a direct pre-accident collective limitation or restriction of the activities - which by hypothesis are now viewed as wrongful, because uncontrollable undesirable acts occur too frequently in them-is bound to be better than a fault system, for the reasons suggested in the discussion on why noninsurable fines are more effective collective deterrers than the fault system. In other words, the most that can be said about acts which are deemed undesirable only when it is too late to avoid them is that they may cause us to judge undesirable some activities in which they tend to occur too frequently. If that is so, we may decide collectively that the activities in which they occur are wrongful and put a crimp on them (in which case collectively imposed fines, taxes, or penalties are in order), or we may

\footnotetext{
${ }^{10} \mathrm{It}$ is often said, and as often denied, that insurance premiums are based not on the fault record of drivers but rather on the record of their involvement in fault-caused accidents. The reason only fault-caused accidents are used is that only these involve payments by insurance companies, and therefore only these become part of insurance company actuarial tables. The reason "involvement" in such accidents rather than "fault" may be used is hard to imagine if fault is a viable concept. The reason would seem to be that even if "fault" is a somewhat better determiner of who will be involved in future accidents than is "involvement in past fault-caused accidents," is it not sufficiently better to make categorization by fault worth its costs even after the expense of assessing fault has already been borne! If this is so, it should by itself serve to damn fault irreparably. In any event, the manner in which insurance rates change as a result of accidents is clearly sufficiently haphazard and arbitrary, under the fault system, so that the possibility of rate rises cannot conceivably be as good a collective deterrent ax an intelligently fixed noninsurable fine.
} 
decide to let the market determine how much of each of the dangerous activities is wanted (in which case market controls are in order). In neither instance is a case for the fault system made out.

: If the fault system cannot be justified when collective deterrence is sought because of the moral undesirability of certain acts, can it be justified where collective deterrence is sought on economic grounds? Is there a place for the fault system when we do not use the market because market controls are too expensive? The answer is obviously "no." The typical case where market controls are too expensive involves the' control of individual acts. It is far too expensive to put to the man who would run a red light the actual cost to society (in terms of risk of accident costs) of his runining that light. If we could, he would almost never run the light and pay the cost. The most a market system of controls can efficiently do is to assess higher ratesreflecting higher accident costs-to those who perform activities in which the temptation to run red lights is too great. And a market system will only do this if charging such a category more is the cheapest way to avoid the costs of running red lights. A fault-insurance system can do no better. It will charge the same category of "possible ted light runners." Indeed, it will charge that category even if charging another category would do more to diminish these particular accident costs (therein lies its difference from the market system). But there is available another way through which we think we can do better than either the markct or the fault system, and that is by direct collective prohibition and noninsurable punishment of people who run red lights. Such a noninsurable penalty represents a collective opinion that if individuals were made to pay the true costs of running red lights each time they ran one, they would usually find the cost greater than the need to run the light. Accordingly, the act is forbidden, and an appropriate collective or specific deterrence penalty is established. The fault system, because it must, like the market system, work primarily through raising the cost to categories of actors rather than affecting the individual at the point of decision, is necessarily at least as ineffective in dealing with such acts as is the market system, and considerably less effective than a system of penalties.

I submit that the kind of reasoning applied to these two major areas wherc collective deterrence is desired would apply equally well to any other area where it may be wanted. Accordingly, I conclude that the fault system cannot be justified as a system of collective control of accident costs. There is still the possibility, though, that the fault system, even if it does a bad job of market control and a bad job of collective control, does an adequate job of mixing the two or at least a better job of mixing them than other possible systems.

\section{IV}

There are two basic ways in which we may prefer a mixed system of accident cost control to a pure system. We may wish to limit rather than restrict an 
activity-and this, as we have seen, implies some collective and some market control. Or we may wish to control some activities or parts of them collectively, while leaving other activities or parts of activities to market control. The question then is, does the fault system help us in either of these situations? Does it help us when we want a mixed control of one activity, and does it help us when we want to control different activities in different ways?

The answer to these questions depends on whether there is anything which prevents us from using the best market control devices together with the best collective control devices, either with respect to an activity which we wish to control in a mixed way or with respect to activities some of which or some parts of which we wish to control in market ways and others of which we wish to control collectively. If there is nothing which prevents us from using the best market and best collective methods together, then the case for the fault system as a good compromise must fall.

Let us look first at activities we wish to control in a mixed way-activities we wish to limit rather than restrict. A simple example shows that there is nothing which keeps us from using the best market and collective controls together. Suppose that for various collective reasons, be they moral or otherwise, we wish to limit drinking by adults. Suppose also that we do not care which adults drink and which do not. (To the extent that we do care, we would use pure collective deterrence, as we in fact do with children.) If this is our only aim, the easiest way would be either to limit the amount of whisky produced and let the price rise until the demand for whisky meets the newly limited supply, or to tax whisky to the point where buyers would only demand the amount we collectively sought to have produced. Either way would be a simple combination of collective and market control and would be more efficient than fanciful ways such as raising the price of a drink by calling all drinkers involved in accidents faulty.

If instead our concern with drink were broader, if we also worried about accident costs which drinking "caused," the situation would be somewhat more complex. We could in this situation use the fault system and allocate all accident costs where one party had drunk whisky to that party. This would to some extent reduce accident costs, and to some extent reduce drinking. But it would do neither optimally. Again we would do better to charge the cheapest cost avoider in accidents which involved a whisky drinker whether this was the whisky drinker or not. For this would reduce accident costs optimally-that is, most cheaply. And to the extent this allocation still left too much whisky being drunk (in terms of our collective judgment to limit whisky drinking) we could further reduce whisky consumption by a then appropriate tax. This last would accomplish the collective aim of limiting total whisky consumption better than the fault system, because it would let the harmless whisky drinkers who enjoyed drinking most have at it. 
Indeed, only if we wanted to reduce accidents in which whisky was involved, regardless of whether this was the best way of reducing accident costs and regardless of whether this was the best way of reducing the amounts of whisky drunk, could we justify a system which made all accident-involved whisky drinkers liable. And this, if I may abstract from the particular example to a general statement of the same proposition, is the same as saying that the fault system can only be justified if what we wish to minimize is not the sum of the costs of accidents and of their avoidance, ${ }^{41}$ nor "faulty" or wrongful behavior, ${ }^{42}$ nor both of these, ${ }^{43}$ but rather accidents in which "faulty" behavior is involved. The more one thinks about this proposition, the more absurd the fault system becomes.

This conclusion is the direct result of the fact that optimal methods of market control can be used consistently with optimal methods of collective control where the aim is to limit an activity. The same conclusion follows, for the same reason, where the aim is to control some activities (or parts of activities) through the market and other activities (or parts of activities) collectively. We can control driving by minors through rules and penalties forbidding driving below sixteen, and at the same time we can control driving in higher age groups strictly through market devices. In fact, we usually would want to use considerably more complex mixtures. For instance we can, (a) through collective prohibition, control driving by certain categories (e.g., driving by minors of less than sixteen or driving by convicted speeders or drunken driving); (b) solely through the market, control driving by other categories (for example, categories of people over eighteen and under seventy); and $(c)$ by various mixed market and collective devices, control driving by still other categories-for example, people sixteen to eighteen, whom we will let drive only with parental permission and only if they can pay their potential accident costs, or people over seventy, whom we may let drive if they pass a physical examination (collective control) and if they can afford the insurance (market control). The combination of optimal collective and market devices can become as complicated as the societal aim demands. ${ }^{44}$ The crucial point is that there is no reason to use the

"The market goal.

QThe collective goal.

"The mixed goal.

"The combinations that are likely to be desired would undoubtedly seek to give weight both to moral and efficiency grounds for collective controls. Assuming it is found that the cheapest way of 2voiding automobile accidents is to put accident costs on various categories of drivers according to the accident proneness of each category, a variety of supplementary collective controls will certainly also be desired. First, certain types of driving (e.g., drunken driving) may be deemed immoral and proscribed attogether. Second, other types of driving may be collectively deemed undesirable and limited through taxation (e.g., driving by teenagers), or may be collectively held especially desirable and encouraged through subsidies (e.g., driving by the handicapped). Finally, certain types of automobile accident costs may be sought to be avoided by collective rules which make sense because market control of these accident costs would be too expensive. Market control of accident costs would be too expensive in two general areas. The first is represented by acts and activities which the market usually cannot reach efficiently for any of the reasons explained in the text (e.g., running red lights, or pedestrian behavior). 
particular combination embodied in the fault system simply because we wish a complex mixture. ${ }^{45}$ That being so, the fault system cannot find justification in the fact that it is a system of mixed market and collective control. It can only find justification either if the one mixed goal it accomplishes well is what we desire (and this, to recapitulate, is the peculiar goal of minimizing neither accident costs, nor wrongful behavior, nor both, but rather accident costs in which wrongful behavior happens to be involved), or if there is something so special about its particular case-by-case jury determination of both moral and causal elements that it meets our justice requirements far better than any other mixed system. ${ }^{46}$

This last is, of course, a crucial point. I have excluded from this article considerations of justice, just as I have excluded considerations of spreading. It may be argued that considering the fault system without examining "justice" is as sterile as considering social insurance without examining spreading. The analogy is interesting. A general system of social insurance for accidents could, as I have written elsewhere, give us optimal spreading-secondary cost control-(but only at the price of losing whatever imperfect control of primary costs of accidents we have

The second is represented by activities (e.g., auto making) which could be controlled effectively by the market only at the cost of failing to put pressure on more fruitful, that is cheaper, cost avoiders like drivers.

In theory, if accident costs were put on drivers they would put the appropriate pressure on auto makers to make safer cars by demanding that car prices reflect their safety records, just as, if accident costs were put on auto makers, these would sell cars at different prices to different categories of drivers according to the accident proneness of each category. See, The Wonderful World, supra note 2, at 228-29; The Decision for Accidents, supra note 3 , at 728 . In practice, this will not happen. If accident costs are put on drivers the degree of subcategorization by category of driver that becomes economically feasible is maximized, but any substantial subcategorization by make or characteristic of car becomes too expensive. Conversely, if accident costs are put on car makers we maximize the economically feasible subcategorization by make and characteristic of car, but we reduce the degree of subcategorization by category of driver that can be made, and hence we reduce the market control that can be put on the driver. The choice between burdening drivers and car makers represents, in effect, a choice of which subcategorization is more important in terms of market control-which, in other words, yields the cheapest cost avoidance.

Such a choice suggests, however, that it may be desirable to control collectively certain subcategories of the activity not burdened. After all, the only reason market control does not reach these subcategories is one of efficiency-given the original allocation of costs-rather than desirability. In effect, by choosing to allocate accident costs to drivers rather than car makers we would be placing subcategories of cars (e.g., cars without seat belts) in the same position as "acts"-that is, things which the market should control but cannot reach as efficiently as can collective regulations. That being so, substantial pressure for collective control of auto specifications and safety would undoubtedly arise. See, Views and Overviews, stupra note 2 at n.4.

${ }^{2}$ The very fact that we supplement the fault system today with many criminal penalties in order to obtain better collective control than it would otherwise afford, is the best possible evidence that there is no inconsistency in mixing some direct collective prohibitions with other devices. If we can use noninsurable penalties to supplement fault-based civil liability, we can as easily use them to supplement market-control-based civil liability. See note 39 supra.

${ }^{10}$ The justice served is at first glance a peculiar one. Liability is based on individual behavior as assessed in a particular situation. Changes in future behavior, however, are sought to be achieved by pressure on categories of acts (that is, activities) since actual payments are made by insurance categories. This schizophrenia of the fault system (largely responsible for its weaknesses as a market, collective, or mixed system of primary cost control) is bound to affect its validity in terms of fairness. 
even under fault). ${ }^{4 \pi}$ Nevertheless, if secondary costs are much more important than primary ones (and in some areas they almost certainly are), then social insurance may be preferable to any of the pure or mixed systems of primary accident cost control I have here discussed. Similarly, if it could be said that the fault system achieved justice precisely because of those attributes which make it a relatively poor controller of primary costs of accidents (and incidentally a terrible controller of secondary and tertiary costs), we might conclude that the fault system was desirable, at least in those areas where vindicating a sense of justice is more important than achieving cost reduction. For this reason, ${ }^{48} \mathrm{I}$ do not pretend this article to be more than a partial treatment of the fault system.

As I have said, however, I do not believe the fault system can be justified today in terms of justice or fairness. ${ }^{49}$ In addition, I have suggested that the more one brings into consideration those secondary and tertiary elements of accident costs which I have excluded from this article, the worse the fault system looks in terms of total accident cost control. If I am right about justice and the fault system, and if the analysis of the fault system and primary accident costs presented in this article stands up, it follows that the crucial debate in the years to come will lie between mixed systems which give good primary accident cost control only at the price of allowing some substantial secondary and tertiary costs, and systems, like social insurance, which can limit secondary and tertiary accident costs well but at the price of inadequate primary cost control. ${ }^{50}$ The fault system will be largely irrelevant to this debate-though it might, as some have suggested, be preserved in a corner as a kind of harmless and slightly luxurious relic which is not allowed to interfere too greatly with the allocation of accident costs. ${ }^{51}$ In practice, this would mean that whatever the importance, to understanding the issues, of the debate between Blum and Kalven and Calabresi, the legislative decisions of the next decades

${ }^{47}$ See, e.g., The Decision for Accidents, supra note 3, at 744-45.

${ }^{8}$ Another reason, itself sufficient, for considering this article as an incomplete treatment of the fault system is the fact that I have only peripherally discussed the merits of the fault system as a valuer of what the costs of accidents are. See note ro supra. A complete treatment of the fault system would require an assessment in full of this aspect of fault.

${ }^{10}$ It may be that the fault system was justifieble in terms of fairness in a less complex age, before the development of insurance, but consideration of that possibility goes beyond the limits I have sct for this article.

${ }^{50} \mathrm{~A}$ system of complete social insurance would limit secondary and tertiary accident costs optimally but would, without more, afford no primary cost control. Primary cost control (of a collective type only) can be introduced by fines and penalties. But the more severe these become (e.g., decapitation of speeders), the more they will be accompanied by substantial secondary and tertiary costs (e.g., if people speed and are caught, secondary costs of capital punishment are inflicted; if too many people fail to drive for fear of accidentally speeding, secondary costs are borne by the automobile industry and the UAW).

${ }^{51}$ Both the Conard and the İeeton and O'Connell studies end in proposals which allow the fault system a relativcly insignificant side role. The basic reasoning of each proposal, however, undercuts cven such a side role. Compare A. Consand et al., supra note 15, at 128, and Conard \& Jacobs, Nelv Hope for Consensus in the Automobile Injury Impasse, 52 A.B.A.J. 533 (1966), with R. KeEToN \& J. O'Conneli, Bastc Protection for the Trafaic Victim 274-76, 323-26 (1965). 
will in fact represent choices between approaches like that of Conard and that of Keeton and O'Connell..$^{52}$

\footnotetext{
"2 See, e.g., Conard et al., supra note I5; and KeEton \& O'Connell, supra note 5I. Needless to say, I am suggesting not that the decisions will rest between the specific proposals with which these authors are associated, but rather that they will be between an essentially "spreading/social insurance" approach and a mixed approach which nonetheless takes substantial notice of primary accident cost controls and specifcally takes notice of market controls of primary costs.
} 